\title{
The Association of Alexithymia and Sense of Coherence With Life Satisfaction in Attention Deficit Hyperactivity Disorder
}

\author{
Kolsom Allah-Gholilo ${ }^{1, *}$; Abbas Abolghasemi ${ }^{1}$; Hossein Dehghan ${ }^{2}$; Hassan Imani ${ }^{1}$ \\ ${ }^{1}$ Department of Psychology, University of Mohaghegh Ardabili, Ardabil, IR Iran \\ ${ }^{2}$ Department of Human Sciences, Ardabil Branch, Islamic Azad University, Ardabil, IR Iran \\ *Corresponding author: Kolsom Allah-Gholilo, Department of Psychology, University of Mohaghegh Ardabili, Ardabil, IR Iran. E-mail: allahgholilo@yahoo.com
}

Received: November 19, 2013; Accepted: January 5, 2014

\begin{abstract}
Background: Attention Deficit Hyperactivity Disorder (ADHD) influences the lives of many of students.
Objectives: The aim of the present study was to determine the relationship between alexithymia, sense of coherence and life satisfaction in students with ADHD symptoms and normal student.

Patients and Methods: This research is a causal-comparative study. The research sample consisting of 47 students with ADHD symptoms and 47 normal students was selected through a simple random sampling method. Data were analyzed using Pearson's correlation coefficients and multiple regression analyses.

Results: The results showed that alexithymia $(r=0.33)$ and sense of coherence $(r=-0.26)$ were related to life satisfaction in ADHD and normal students. The results of multiple regression showed that alexithymia and sense of coherence explained $20 \%$ of the variance in life satisfaction in students.

Conclusions: The results show that sense of coherence has positively but alexithymia was negatively related with life satisfaction in ADHD student.
\end{abstract}

Keywords: Sense of Coherence; Affective Symptoms; Life satisfaction; Attention Deficit Disorder with Hyperactivity

\section{Background}

Attention Deficit Hyperactivity Disorder (ADHD) is a psychiatric diagnosis applied to individuals who exhibit developmentally inappropriate levels of inattention and/ or excessive amounts of motor activity/impulsivity [1]. Many children with ADHD grow out of their symptoms of inattention, hyperactivity and impulsivity, but the symptoms sometimes persist into young adulthood [2]. Young and Gudjonsson [3] found that ADHD may be a risk factor for poor adjustment in adult life irrespective of the presence of all the symptoms in adulthood. According to Diener et al. study, life satisfaction is a broad range of human experiences related to one's overall subjective well-being [4]. It implies values based on subjective functioning in comparison with personal expectations and is defined by subjective experiences, states and perceptions. Gudjonsson et al. [5] showed that the variables in the study accounted for $22 \%$ and $25 \%$ of the variance of the satisfaction with life scale (SWLS) among males and females, respectively. Sense of coherence (SOC) is one of the variables associated with life satisfaction. Antonovsky [6] defined sense of coherence as a global orientation that expresses the extent to which one has a pervasive, enduring though dynamic feeling of confidence that the stimuli deriving from one's internal and external environments in the course of living are structured, predictable and expli- cable. Schnyder et al. believed that SOC develops during childhood and youth and is thought, based on theoretical considerations, to be fully developed by the age of 30 years [7]. Research on different segments showed that sense of coherencies related to quality of life [8] and life satisfaction [9].

Alexithymia is associated with life satisfaction. It is, by definition, considered a stable personality trait characterized by impoverishment of fantasy, poor capacity for symbolic thought, and an inability to experience and verbalize emotions [10]. Research suggests that alexithymia is associated with interpersonal problems. Mattila et al. [11] found that individuals with alexithymia have low physical functioning, emotional problems, low energy, lower emotional well-being, low social functioning, more pain and less public health.

\section{Objectives}

This study examined the association of sense of coherence and alexithymia with life satisfaction in students with ADHD symptoms and normal students.

\section{Patients and Methods}

In this causal-comparative study, population consisted 
of all second and third graders in the city of Ardabil during the 2009 - 2010 school years. The sample consisted of 94 students (47 students with ADHD symptoms and 47 normal children) selected through a random sampling method.

These participants ranged in age from 13 to 15 years old $(13.7 \pm 0.7)$. The fathers of $76.1 \%$ of the students were selfemployed while 23.9 of them held government jobs. The mothers of $92.5 \%$ of the students were housewives and those of $5.7 \%$ of them were working. First borns were $25.3 \%$ of the children, $45.3 \%$ were the second, $10.5 \%$ were the third, $7.4 \%$ were the fourth and $10.8 \%$ were the fifth child at home.

\subsection{Attention Deficit/Hyperactivity Scale}

Attention deficit/hyperactivity scale was developed by Najarian [12] based on the DSM-IV criteria. The reliability (Cronbach alpha) of this scale has been reported to be 0.90 .

\subsection{Sense of coherence}

The short-form of the SOC was developed by Antonovsky. This 14 item version includes items measuring each of the three dimensions of SOC. The scale consists of comprehensibility items, manageability items, and meaningfulness items and the internal consistency of this scale has been reported as 0.85 [6].

\subsection{The Toronto Alexithymia Scale}

The Toronto Alexithymia Scale (TAS-20) is a 20-item questionnaire is used to measure three facets of alexithymia. The scale was developed by Rieffe et al. [13]. The reliability (Cronbach alpha) of this scale has been reported to be
0.75. Subscale scores correlate with test with the scores obtained on Czech psychiatric symptoms list and correlation coefficients from 0.48 to 0.70 have been reported [13].

\subsection{The Satisfaction With Life Scale}

The satisfaction with life scale (SWLS) is a five-item scale used as a measure of the judgmental component of subjective well-being. The internal consistency of this scale has been reported as lying between 0.80 to 0.89 and the test-retest reliability has been reported as 0.64 to 0.84 [14]. All data were analyzed with SPSS 16 . P-Value $<0.05$ was taken as statistically significant.

\section{Results}

Alexithymia and sense of coherence are related to life satisfaction (Table 1). Comprehensibility and manageability correlated positively but meaningfulness was only marginally associated with life satisfaction. Difficulty communicating feelings and externally oriented thinking were positively correlated with life satisfaction but difficulty identifying feelings was only marginally associated with life satisfaction.

As can be seen in Table 2, alexithymia and sense of coherence explained $20 \%$ of the variance in students' life satisfaction $(\mathrm{P}=0.001)$. The results of multiple regression analysis showed that alexithymia $(B=-0.433)$ and sense of coherence $(B=0.951)$ predicted changes related to the life satisfaction of students $(\mathrm{P}=0.01)$. Also, alexithymia and sense of coherence explained $23 \%$ of the variance in students' life satisfaction $(\mathrm{P}=0.001)$. Comprehensibility ( $\mathrm{B}$ $=1.937)$ and manageability $(B=0.900)$ predicted changes related to life satisfaction in students' lives $(\mathrm{P}<0.01)$.

Table 1. Correlation of Variables Alexithymia and Sense of Coherence With Life Satisfaction in ADHD and Normal Students

\begin{tabular}{lccc}
\hline Alexithymia & Life Satisfaction $(\mathbf{r})$ & Sense of Coherence & Life Satisfaction (r) \\
\hline Difficulty in identifying feelings & -0.06 & Meaningfulness \\
Difficulty in describing feelings & 0.04 & Comprehensibility $^{-0.18}$ & Manageability $^{0.37^{\mathrm{b}}}$ \\
Externally-oriented thinking & 0.10 & Total $^{\mathrm{b}}$ & $0.35^{\mathrm{b}}$ \\
Total & $-0.26^{\mathrm{a}}$ & $0.33^{\mathrm{b}}$ \\
\hline
\end{tabular}

$\mathrm{a}_{\mathrm{P}}<0.05$.

b $\mathrm{P}<0.01$.

Table 2. Analaysis of Multiple Regression of Anticipated the Life Satisfaction in ADHD and Normal Students

\begin{tabular}{|c|c|c|c|c|c|c|c|}
\hline Variable & $\mathbf{R}$ & $\mathbf{R}^{\mathbf{2}}$ & Adjusted $\mathbf{R}^{2}$ & B & SE & & P-Value \\
\hline Sense of coherence & 0.33 & 0.110 & 0.101 & 0.951 & 0.240 & 0.371 & 0.001 \\
\hline Alexithymia & 0.45 & 0.204 & 0.187 & -0.433 & 0.131 & -0.309 & 0.001 \\
\hline Meaningfulness & 0.164 & 0.027 & 0.016 & -0.943 & 0.591 & -0.164 & 0.114 \\
\hline Comprehensibility & 0.420 & 0.176 & 0.158 & 1.937 & 0.477 & 0.390 & 0.001 \\
\hline Manageability & 0.468 & 0.219 & 0.193 & 0.900 & 0.404 & 0.222 & 0.03 \\
\hline Difficulty in identifying feelings & 0.478 & 0.228 & 0.193 & -0.267 & 0.264 & -0.101 & 0.16 \\
\hline Difficulty in describing feelings & 0.478 & 0.229 & 0.185 & -0.078 & 0.376 & -0.020 & 0.37 \\
\hline Externally-oriented thinking & 0.484 & 0.234 & 0.182 & -0.254 & 0.310 & -0.078 & 0.15 \\
\hline
\end{tabular}




\section{Discussion}

The results showed that sense of coherence was related to life satisfaction in students with ADHD symptoms as well as in normal students. Also comprehensibility and manageability were positively correlated with life satisfaction but meaningfulness was only marginally associated with life satisfaction.

These results are in line the Mowad [8] and Sifneos [10]. To date, most research has focused on SOC as a determinant of health or has investigated living conditions or family dynamics as factors influencing SOC development [15]. Results from these studies have shown that sense of coherencies positively related to psychological and physical well-being and personality traits such as optimism, self-esteem and sense of control. People with ADHD experience stress and anxiety in their life, and having a sense of coherence helps them to cope with their anxiety. These result simply that with a sense of coherence, individuals understand and accept the emotions and events they experience in life better. When people with ADHD have a greater sense of coherence, they are able to better understand the problems disorder, and cope with them, with a more realistic view. Sense of coherence enhances the self-esteem of children, because these children often have low self-esteem due to the characteristics of their problem. Self-confidence, a better understanding of life and meaningfulness can increase sense of coherence and life satisfaction.

In this study meaningfulness was not significantly associated with life satisfaction. In as much as meaningfulness is a motivational component and indicates involvement with people in different areas and the sample of this study comprised early adolescents, this component does not play a significant role in the life satisfaction of this group. Students with ADHD symptom experience problems caused by this disorder but they cannot affect their lives by making attempts for change and growth. These factors are likely reasons for lower life satisfaction.

The results also showed that alexithymia was negatively correlated with life satisfaction in ADHD students and normal students. Difficulty communicating feelings and externally oriented thinking were positively correlated with life satisfaction but difficulty identifying feelings was not associated with life satisfaction. These results are in line with those of Mattila et al. [11]. Thus, the consequences of a lifetime of maladaptive health behaviors may place individuals with alexithymia at greater risk for all-cause mortality [16].

These findings suggest that since children with ADHD symptoms experience hyperactivity and impulsiveness early, they have always had problems and, therefore, unable to enjoy of life, leading to reports of decreased satisfaction with life. People suffering from alexithymia have difficulty in experiencing and expressing emotions, thereby not communicating easily with others. These reasons decrease their satisfaction with life. Fur- thermore, due to their hyperactivity, these individuals have always had to suppress their emotions and felt unable to express emotions in a positive way. This is also a likely reason for low satisfaction. The results of multiple regression analysis showed that alexithymia and sense of coherence explained $20 \%$ of the variance in life satisfaction of students. Sense of coherence increases satisfaction and relaxation. Because people with ADHD exhibit more signs of movement and tension, and cannot reasonably communicate with people, they experience rejection from peers because of having the above characteristics and have limited communication with people around them. They find it difficult to make their life more organized and experience more stress and anxiety. Consequently, the decreased sense of coherence leads to less satisfaction in life. It is suggested that by training individuals to increase their sense of coherence in school and psycho-logical clinics, the problems of students with ADHD symptoms can be reduced and their life satisfaction can be increased. These results have important implications in the prevention of psychological problems of students with ADHD symptoms and problems.

\section{Acknowledgements}

We would like to appreciate all the participants who gave their time to take part in our study.

\section{Authors' Contributions}

All authors had equal role in the design, study, statistical analysis and manuscript writing.

\section{Funding/Support}

The present study is supported by University of Mohaghegh Ardabili, Ardabil, IR Iran.

\section{References}

1. American Psychiatric Association. Diagnostic and Statistical Manual of Mental Disorders: Dsm-5.Washington DC: Amer Psychiatric Pub Incorporated; 2013.

2. Faraone SV. The scientific foundation for understanding attention-deficit/hyperactivity disorder as a valid psychiatric disorder. Eur Child Adolesc Psychiatry. 2005;14(1):1-10.

3. Young S, Gudjonsson GH. Growing out of ADHD: the relationship between functioning and symptoms. J Atten Disord. 2008;12(2):162-9.

4. Diener E, Emmons RA, Larsen RJ, Griffin S. The satisfaction with life scale. J Pers Assess. 1985;49(1):71-5.

5. Gudjonsson GH, Sigurdsson JF, Eyjolfsdottir GA, Smari J, Young S. The relationship between satisfaction with life, ADHD symptoms, and associated problems among university students. J Atten Disord. 2009;12(6):507-15.

6. Antonovsky A. The structure and properties of the sense of coherence scale. Soc Sci Med.1993;36(6):725-33.

7. Schnyder U, Buchi S, Sensky T, Klaghofer R. Antonovsky's sense of coherence: trait or state? Psychother Psychosom. 2000; 69(6):296-302.

8. Mowad L. Correlates of quality of life in older adult veterans. West J Nurs Res. 2004;26(3):293-306. 


\section{Allah-Gholilo Ket al.}

9. Eriksson M, Lindstrom B. Validity of Antonovsky's sense of coherence scale: a systematic review. J Epidemiol Community Health. 2005;59(6):460-6.

10. Sifneos PE. The prevalence of 'alexithymic' characteristics in psychosomatic patients. Psychother Psychosom. 1973;22(2):255-62.

11. Mattila AK, Saarni SI, Salminen JK, Huhtala H, Sintonen H, Joukamaa M. Alexithymia and health-related quality of life in a general population. Psychosomatics. 2009;50(1):59-68.

12. Najarian B. [Psychological tests]. persian.Ardabil: Bagh-e-Rezvan Press; 2006.
13. Rieffe C, Oosterveld P, Terwogt MM. An alexithymia questionnaire for children: factorial and concurrent validation results. Personal Indiv Diffrent J. 2006;40(1):123-33.

14. Diener E, Suh EM, Lucas RE, Smith HL. Subjective well-being: three decades of progress. Psychol Bull.1999;125(2):276-302.

15. Wolff AC, Ratner PA. Stress, social support, and sense of coherence. West J Nurs Res. 1999;21(2):182-97.

16. Kauhanen J, Kaplan GA, Cohen RD, Julkunen J, Salonen JT. Alexithymia and risk of death in middle-aged men. Psycho Res $J$. 1996;41(6):541-9. 